\title{
A STUDY ON CLINICAL PROFILE AND COMPLICATIONS OF LEPTOSPIROSIS AT KILPAUK MEDICAL COLLEGE, CHENNAI
}

\author{
Marimuthu Arumugam¹, Rajan Ganesan², Ibrahim Sameem Khan³, Vinoth Kalaiselvan ${ }^{4}$ \\ ${ }^{1}$ Senior Assistant Professor, Department of Medicine, Government Stanley Medical College Hospital, Chennai. \\ 2Professor, Department of Medicine, Government Stanley Medical College Hospital, Chennai. \\ 3Junior Resident, Department of Medicine, Government Kilpauk Medical College Hospital, Chennai. \\ 4Junior Resident, Department of Medicine, Government Stanley Medical College Hospital, Chennai.
}

\section{ABSTRACT}

\section{BACKGROUND}

Leptospirosis is associated with characteristic symptoms, signs and functional alterations in many organs and systems. The purpose of this study was to analyse functional changes in many organs and systems and to determine outcome and complications.

\section{AIMS AND OBJECTIVES}

1. To study and analyse clinical profiles and complications of leptospirosis.

2. To study biochemical profile of leptospirosis.

\section{MATERIALS AND METHODS}

This study was carried out in medical wards at Kilpauk Medical College, Chennai, from January 2015 to August 2015; 67 patients were diagnosed with leptospirosis and who fulfilled the inclusion criteria were included in the study and the required data were collected from medical wards, IMCU and laboratory.

\section{RESULTS}

Out of 67 patients studied, Hepatitis was seen in 39 cases, Acute Kidney injury was seen in 31 cases, ARDS was seen in 3 cases and Myocarditis was seen in 2 cases. Out of 31 cases of Acute Kidney injury, Dialysis was done in 17 cases. Out of 31 cases of Acute Renal Failure, 2 cases died and out of 3 cases of ARDS 1 case died.

\section{CONCLUSION}

This study concludes that Leptospirosis cases were more prone to develop Hepatitis and Acute Kidney injury and least commonly ARDS and Myocarditis. So in spite of monitoring of Renal and Hepatic functions, screening of cardiac and respiratory function was also needed in initial diagnostic and evaluation of Leptospirosis.

\section{KEYWORDS}

Leptospirosis - Clinical Profile - Multiorgan Involvement - Biochemical Profile - Raised Liver and Renal Parameter.

HOW TO CITE THIS ARTICLE: Arumugam M, Ganesan R, Khan IS, et al. A study on clinical profile and complications of leptospirosis at Kilpauk Medical College, Chennai. J. Evolution Med. Dent. Sci. 2016;5(69):5030-5034, DOI: 10.14260/jemds/2016/1142

\section{INTRODUCTION}

Leptospirosis has been considered an infrequent zoonoses in India for a long period of time. But for the past two decades, there has been a steady increase in incidence of leptospirosis cases in many Indian states particularly Kerala, Gujarat and Tamil Nadu.(1)

With the improvement of diagnostic techniques and clinical expertise, there has been a dramatic increase in number of reported cases of this widespread zoonoses. The clinical spectrum of the disease varies from asymptomatic illness to severe and non-reversible renal failure resulting in death.(2) Leptospirosis is diagnosed with the help of specific yet complex laboratory tests as the clinical features of the disease are non-specific. Subsequently, definite guidelines has been established for the diagnosis of the disease in

Financial or Other, Competing Interest: None.

Submission 04-07-2016, Peer Review 11-08-2016,

Acceptance 19-08-2016, Published 29-08-2016.

Corresponding Author:

Dr. Marimuthu Arumugam,

No. 104, Block C-6,

Prince Village-Phase II,

$8^{\text {th }}$ Elaya Street, Tondiarpet, Chennai-81.

E-mail: drmarimuthu1972@gmail.com

DOI: $10.14260 /$ jemds/2016/1142 endemic areas. In India diagnosis of Leptospirosis is simplified using the modified Faine's criteria, which makes use of the clinical features as well as the epidemiological and lab data for the effective diagnosis of the disease.(3)

Awareness about the infection is scarce, especially in the developing countries as a consequence of which it is rarely thought of in the differential diagnosis of febrile illnesses.

Among the 824 patients investigated for acute febrile illness in Kilpauk Medical College Hospital in Ch e n na i for a period of 8 months, 67 patients were diagnosed to have Leptospirosis. Hence, this study o $\mathrm{n}$ the clinical profile and complications of Leptospirosis was carried out and the results were analysed.

\section{METHODOLOGY/AIMS AND OBJECTIVES}

1. To study and analyse the clinical profile and complications of leptospirosis.

2. To study the Biochemical profile of Leptospirosis.

\section{MATERIALS AND METHODS}

Cross-sectional study (Descriptive) carried out.

A total of 67 patients who were admitted with fever at Kilpauk Medical College Hospital, Department of Medicine, over a period of 8 months who have been diagnosed to have leptospirosis fulfilling the inclusion and exclusion criteria. 


\section{Sample Size}

67 (As per formula) Applying the sample size formula: $\mathrm{N}=\mathrm{Z}^{\wedge} 2\left\{\mathrm{P}^{*} \mathrm{Q}\right\} / \mathrm{l}^{\wedge} 2$

- $\quad$ Z; with $95 \%$ confidence interval.

- P: prevalence of subclinical hypothyroidism.

- Q: 100-p.

- L: relative precision is $50 \%$. So on applying this formula, my sample size was around 67.

The following Investigations are done to Assess the Study

Complete blood picture, Routine urine analysis, Random blood sugar, Blood urea, Serum creatinine, Chest X-Ray, HIV antibodies detected by ELISA, IGM antibodies to leptospirosis, QBC for MP, Liver function test, Platelet count, Ultrasound Abdomen, WIDAL Test, IGM antibodies to Dengue, CSF analysis if necessary, Kidney Biopsy if necessary.(4)

\section{Ethical Issues}

Patients/relatives will be explained about the study.

Patients will be included in the study after obtaining written informed consent.

\section{Safety}

- No harm done to the patient.

- No extra expenses for the patient.

- Informed consent was obtained.

\section{Ethical Clearance}

All necessary ethical clearance was obtained from the Ethical Committee, Kilpauk Medical College and Hospital in Chennai.

\section{Limitations of the Study}

Sample size was achieved with less absolute precision, hence the results of the study will have wide variability. Due to limited resources and practical constraints, this study is being carried out with a small sample size. Thus, the appropriate representation of the population and better outcomes could be attained by increasing the sample size.

\section{Statistical Analysis and Results}

- Statisticalanalysis was done by SPSS software.

- Chi square test and $\mathrm{p}$ value was used for statistical analysis.

- $\quad$ P value less than 0.0001 .

\section{RESULT}

In the present study, 67 confirmed cases of Leptospirosis were admitted to the Department of Medicine in Government Kilpauk Medical College Hospital from January 1st 2015 to August 31st 2015. The total number of acute febrile illness cases admitted during the study period were 824, out of which Leptospirosis constituted $8.1 \%$.

Prevalence of Leptospirosis among Acute Febrile Illness Total number of cases of acute febrile illness - 824

Total number of confirmed cases of Leptospirosis - 67

\section{Demographic Profile of Leptospirosis}

\begin{tabular}{|c|c|c|}
\hline Age Group & Number & Percentage \\
\hline $13-25$ & 20 & 29.8 \\
\hline $26-50$ & 31 & 46.5 \\
\hline $51-75$ & 14 & 20.8 \\
\hline$>75$ & 2 & 2.9 \\
\hline Total & $\mathbf{6 7}$ & $\mathbf{1 0 0}$ \\
\hline \multicolumn{2}{|c|}{ Table 1: Age Distribution of the Cases }
\end{tabular}

\begin{tabular}{|c|c|c|}
\hline Sex & Number & Percentage \\
\hline Male & 48 & $71.6 \%$ \\
\hline Female & 19 & $28.4 \%$ \\
\hline Total & $\mathbf{6 7}$ & $\mathbf{1 0 0}$ \\
\hline \multicolumn{2}{|c|}{ Table 2: Sex Distribution of the Cases } \\
\hline
\end{tabular}

\begin{tabular}{|c|c|c|}
\hline Occupation & No. of Cases & \% \\
\hline Manual Outdoor Worker & 23 & 34.3 \\
\hline Farmer & 13 & 19.4 \\
\hline House Wife & 12 & 17.9 \\
\hline Student & 4 & 6 \\
\hline Teacher & 7 & 10.4 \\
\hline Shopkeeper & 8 & 11.9 \\
\hline Total Table 3: Occupation \\
\hline \multicolumn{2}{|c|}{} \\
\hline
\end{tabular}

Out of 67 cases 31 cases (46.5\%) belonged to the age group 26-50 years, which constituted the majority followed by 20 cases (29.8\%) in the age group 13-25 years followed by 14 cases $(20.8 \%)$ in the age group 51-75 years and 2 cases above 75 years of age constituting $2.9 \%$. P value was 0.0001 , which is significant $(\mathrm{p}<0.05)$.

Among the 67 cases, males were majority constituting $71.6 \%(n=48)$ followed by females constituting $28.4 \%$ $(n=19)$. Male: Female ratio was noted to be $2.5: 1$. There was a significant difference between the gender according to $P$ value, which was $<0.0001(\mathrm{p}<0.05)$.

Out of 67 cases 23 cases were manual outdoor workers constituting the majority (34.3\%) followed by 13 cases of farmers constituting $19.4 \%$, house wives were 12 cases constituting $17.9 \%$, shopkeepers were 8 in number constituting $11.9 \%, 7$ cases were teachers constituting $10.4 \%$, 4 cases were students constituting $6 \%$. P value was 0.0001 , which was significant $(\mathrm{p}<0.05)$.

\section{Signs and Symptoms}

\begin{tabular}{|c|c|c|}
\hline Symptoms & No. of Cases & Percentage \\
\hline Fever & 67 & $100 \%$ \\
\hline Headache & 61 & $91 \%$ \\
\hline Myalgia & 58 & $86.6 \%$ \\
\hline Arthralgia & 25 & 37.3 \\
\hline Breathlessness & 6 & 8.9 \\
\hline Vomiting & 37 & 55.2 \\
\hline Jaundice & 39 & 58.2 \\
\hline $\begin{array}{c}\text { Urinary } \\
\text { Disturbances }\end{array}$ & 22 & 32.8 \\
\hline $\begin{array}{c}\text { Bleeding } \\
\text { Symptoms }\end{array}$ & 6 & 8.9 \\
\hline \multicolumn{2}{|c|}{ Table 4: Clinical Presentation of the Cases } \\
\hline
\end{tabular}




\begin{tabular}{|c|c|c|}
\hline Signs & No. of Cases & \% \\
\hline Pallor & 22 & $32.8 \%$ \\
\hline Icterus & 39 & $58.2 \%$ \\
\hline ConjunctivalCongestion & 56 & $83.6 \%$ \\
\hline Hypotension & 10 & $14.9 \%$ \\
\hline Pedal oedema & 37 & $55.2 \%$ \\
\hline Hepatomegaly & 59 & $88 \%$ \\
\hline Splenomegaly & 31 & $46.3 \%$ \\
\hline \multicolumn{2}{|c|}{ Table 5: Clinical Signs } \\
\hline
\end{tabular}

Fever was the most common symptom seen in all cases constituting $100 \%$. Headache was the next common symptom seen in 61 cases constituting $91 \%$, followed by myalgia seen in 58 cases constituting $86.6 \%$, followed by jaundice in 39 cases constituting $58.2 \%$, vomiting in 37 cases constituting $55.2 \%$, arthralgia in 25 cases constituting $37.3 \%$.

Urinary disturbances were seen in 22 cases, constituting $32.8 \%$. All the cases had oliguria.

Bleeding symptoms were seen in 6 cases constituting $8.9 \%$; 4 cases had haematuria as the bleeding symptom and ecchymosis was seen in 2 cases.

Among the 67 cases, 40 patients had fever of duration between 6-10 days constituting 59.7\%, followed by 17 patients with duration between 11-15 days, constituting $25.4 \%$ and 10 cases with fever duration between 1-5 days constituting $14.9 \%$. P value was 0.0001 , which is significant $(\mathrm{p}<0.05)$.

Most common clinical sign was hepatomegaly seen in 59 cases constituting 88\%, followed by conjunctival congestion seen in 56 cases constituting 83.6\%, followed by icterus seen in 39 cases constituting $58.2 \%$, pedal oedema seen in 37 cases constituting $55.2 \%$, splenomegaly seen in 31 cases constituting $46.3 \%$, pallor seen in 22 cases constituting $32.8 \%$ and hypotension seen in 10 cases constituting $14.9 \%$.(5) $\mathrm{P}$ value was 0.0001 , which is significant $(\mathrm{p}<0.05)$.

Among the 67 cases, 3 cases (8.9\%) developed ARDS and 2 cases (3\%) developed myocarditis.

Laboratory Findings of Leptospirosis

\begin{tabular}{|c|c|c|}
\hline Parameters & No. of Cases & Percentage \\
\hline Anaemia & 22 & $32.8 \%$ \\
\hline Leucocytosis & 32 & $47.8 \%$ \\
\hline Leucopenia & 19 & 28.4 \\
\hline Thrombocytopenia & 59 & $88 \%$ \\
\hline \multicolumn{2}{|c|}{ Table 6: Laboratory Analysis of } \\
Haematological Parameters \\
\hline
\end{tabular}

\begin{tabular}{|c|c|c|}
\hline & No. of Cases & Percentage \\
\hline Urea $<40 \mathrm{mg} / \mathrm{dL}$ & 27 & $40 \%$ \\
\hline Urea $>40 \mathrm{mg} / \mathrm{dL}$ & 40 & $60 \%$ \\
\hline Total & 67 & 100 \\
\hline
\end{tabular}

\begin{tabular}{|c|c|c|}
\hline & No. of Cases & Percentage \\
\hline $\begin{array}{c}\text { Creatinine } \\
<1.4 \mathrm{mg} / \mathrm{dL}\end{array}$ & 37 & 55 \\
\hline $\begin{array}{c}\text { Creatinine } \\
>1.4 \mathrm{mg} / \mathrm{dL}\end{array}$ & 30 & 45 \\
\hline Total & $\mathbf{6 7}$ & $\mathbf{1 0 0}$ \\
\hline \multicolumn{2}{|c|}{$\begin{array}{c}\text { Table 8: Distribution ofthe Cases } \\
\text { According to Serum Creatinine }\end{array}$} \\
\hline
\end{tabular}

Anaemia was seen in 22 cases, constituting 32.8\%. All the 22 cases had haemoglobin less than $11 \mathrm{gms} \%$. P value was 0.0007 , which is significant $(<0.05) ; 7$ cases had haemoglobin below 7 gms $\%$, constituting $32 \%$.

Thrombocytopenia was seen in 59 cases, accounting for $88 \%$ ( $\mathrm{P}$ value $<0.0001$ ). Out of the 59 cases, 10 cases had platelet less than 50,000 , constituting $16.8 \%$.

Out of the 67 cases, 40 cases had urea more than 40 $\mathrm{mg} / \mathrm{dL}$, constituting $60 \%$. Maximum value of elevated serum urea encountered was $298 \mathrm{mg} / \mathrm{dL}$. $\mathrm{P}$ value was 0.0455 , which was significant $(<0.05)$.

Out of the 67 cases, 30 cases had creatinine more than $1.4 \mathrm{mg} / \mathrm{dL}$, constituting $45 \%$. The maximum value of serum creatinine encountered in the present study was $11 \mathrm{mg} / \mathrm{dL}$. P value was 0.3173 , which was not significant (i.e. $>0.05$ ).

Out of the total 67 cases, serum urea was found elevated in majority of cases $(60 \%)$ when compared to serum creatinine (40\%).

\section{Laboratory Analysis of Liver Function Tests}

Out of 67 cases, 48 cases had total bilirubin more than 1.1 $\mathrm{mg} / \mathrm{dL}$, constituting $71.6 \%$. $\mathrm{P}$ value was 0.0030 , which was significant (i.e. $<0.05$ ). Out of 67 cases, 54 cases had direct bilirubin more than $0.2 \mathrm{mg} / \mathrm{dL}$, constituting $80.6 \%$. P value was 0.0242 , which was significant (i.e. $<0.05$ ).

\begin{tabular}{|c|c|c|c|c|c|}
\hline $\begin{array}{c}\text { Serum } \\
\text { Total } \\
\text { Bilirubin }\end{array}$ & $\begin{array}{c}\text { No. of } \\
\text { Cases }\end{array}$ & $\%$ & $\begin{array}{c}\text { Serum } \\
\text { Total } \\
\text { Bilirubin }\end{array}$ & $\begin{array}{c}\text { No. of } \\
\text { Cases }\end{array}$ & $\%$ \\
\hline $1.11-3 \mathrm{mg} / \mathrm{dL}$ & 9 & 18.8 & $0.21-2 \mathrm{mg} / \mathrm{dL}$ & 16 & 30 \\
\hline $3.1-7 \mathrm{mg} / \mathrm{dL}$ & 12 & 25 & $2.1-5 \mathrm{mg} / \mathrm{dL}$ & 27 & 50 \\
\hline$>7 \mathrm{mg} / \mathrm{dL}$ & 27 & 56.2 & $>5 \mathrm{mg} / \mathrm{dL}$ & 11 & 20 \\
\hline Total & $\mathbf{4 8}$ & $\mathbf{1 0 0}$ & Total & $\mathbf{5 4}$ & $\mathbf{1 0 0}$ \\
\hline \multicolumn{6}{|c|}{ Table 9: Distribution of the Cases According } \\
to Serum Total and Direct Bilirubin \\
\hline
\end{tabular}

Out of 67 cases, 48 cases had serum SGOT more than 40 $\mathrm{u} / \mathrm{L}$, constituting $71.6 \%$. $\mathrm{P}$ value was 0.0072 , which is significant (i.e. $<0.05$ ).

Out of 67 cases, 49 cases had serum SGPT more than 40 $\mathrm{u} / \mathrm{L}$, constituting $73.1 \%$. $\mathrm{P}$ value was 0.0442 , which is significant (i.e. $<0.05)$.

\begin{tabular}{|c|c|c|c|c|c|}
\hline $\begin{array}{c}\text { Serum } \\
\text { SGOT } \\
\text { (u/L) }\end{array}$ & $\begin{array}{c}\text { No. of } \\
\text { Cases }\end{array}$ & $\%$ & $\begin{array}{c}\text { Serum } \\
\text { SGPT } \\
\text { (u/L) }\end{array}$ & $\begin{array}{c}\text { No. of } \\
\text { Cases }\end{array}$ & $\%$ \\
\hline $41-150$ & 9 & 18.8 & $41-150$ & 10 & 20.4 \\
\hline $151-450$ & 13 & 27.1 & $151-450$ & 15 & 30.6 \\
\hline $451-900$ & 26 & 54.1 & $451-900$ & 24 & 49 \\
\hline Total & 48 & 100 & Total & 49 & 100 \\
\hline \multicolumn{7}{|c|}{ Table 10: Distribution of the Cases } \\
According to Serum SGOT and SGPT \\
\hline
\end{tabular}

\section{Treatment of the Cases}

\begin{tabular}{|c|c|c|}
\hline Treatment & No. of Cases & Percentage \% \\
\hline IV Fluids & 64 & 95.5 \\
\hline Antibiotics & 67 & 100 \\
\hline Platelet Rich Plasma (PRP) & 10 & 15 \\
\hline Blood Transfusion (BT) & 7 & 10.4 \\
\hline \multicolumn{2}{|c|}{ Table 11: Treatment Given to the Cases } \\
\hline
\end{tabular}




\begin{tabular}{|c|c|c|}
\hline $\begin{array}{c}\text { Treatment-Complicated } \\
\text { Cases }\end{array}$ & $\begin{array}{c}\text { No. of } \\
\text { Cases }\end{array}$ & $\begin{array}{c}\text { Percentage } \\
\%\end{array}$ \\
\hline Acute Kidney Injury & 17 & 25 \\
\hline ARDS & 3 & 4.5 \\
\hline Myocarditis & 2 & 3 \\
\hline Table 12: Treatment Given at IMCU \\
Ward for Complicated Cases \\
\hline
\end{tabular}

General treatment with intravenous fluids was given in 64 cases, constituting 95.5\%. Specific treatment with Antibiotics was given in all cases (100\%). Majority of the patients, 51 patients were given IV penicillin (76.1\%); 16 cases who had mild symptoms and no complications were given oral Doxycycline (23.9\%).(6)

Platelet rich plasma was administered in 10 cases constituting $15 \%$. All the 10 cases had platelet count less than 50,000 . Out of the 10 cases with platelet count less than $50,000,6$ cases had bleeding symptoms constituting $60 \%$. Bleeding was encountered in the form of haematuria seen in 4 cases constituting $66.7 \%$ out of the 6 cases and ecchymosis seen in 2 cases constituting $33.3 \%$.

Blood transfusion was carried out in 7 cases constituting $10.4 \%$. All the 7 cases had haemoglobin less than 7 gms\%.

\section{Complications}

Out of 67 cases, 51 cases (76.1\%) developed complications during the hospital stay; 16 cases had no complications, constituting $23.9 \%$.

\begin{tabular}{|c|c|c|}
\hline Complications & No. of Cases & $\mathbf{\%}$ \\
\hline Acute Renal Failure (ARF) & 31 & 46.3 \\
\hline Hepatitis & 39 & 58.2 \\
\hline ARDS & 3 & 4.5 \\
\hline Myocarditis & 2 & 3 \\
\hline \multicolumn{2}{|c|}{ Table 13: Complications } \\
\hline
\end{tabular}

Hepatitis was the most common complication encountered seen in 39 cases, constituting 58.2\%. ARF was the next common complication seen in 31 cases, constituting $46.3 \%$. ARDS was seen in 3 cases, constituting $8.9 \%$. Myocarditis was the least common complication encountered seen in 2 cases, constituting $3 \%$. $\mathrm{P}$ value was less than 0.0001 , which was significant.

Intubation and mechanical ventilation was done in 2 cases, out of 3 cases of ARDS, constituting 66.6\%. Dialysis was carried out in 17 patients of ARF out of 31 cases, constituting $54.8 \%$.

\section{Mortality}

Out of 67 patients, 3 patients died, constituting 4.5\%; 2 cases died due to acute renal failure. One case had both hepatitis and ARDS and died.

\section{DISCUSSION}

Apart from being a rural disease affecting the farmers in particular, Leptospirosis in the modern times has become an urban endemic. It has been on the rise in states like Karnataka and Tamil Nadu contributed by increased cultivation and inadequate vector control.

Hence, this study was taken up in Government Kilpauk Medical College Hospital, mainly nurturing the urban population within the city limits. The primary aim was to analyse the clinical profile and complication of the disease and Biochemical profile of leptospirosis. Totally 67 proven cases of leptospirosis admitted to Govt. Kilpauk Medical College during a period of 8 months were involved in the study.

Out of the 824 fever cases admitted during the study period, leptospirosis constituted $8.1 \%$ (67 cases). Among those admitted, males constituted $71.6 \%$ and females $28.4 \%$ with the ratio being 2.5:1.

Regarding occupation, $34.3 \%$ of the cases were manual outdoor workers followed by farmers accounting for $19.4 \%$. This clearly indicates the incidence of the disease is very high among outdoor manual working population and farmers. (53.7\% combined together). A similar study by Muthusethupathi et al during 1990 in Madras showed an incidence of $59 \%$ in outdoor workers.(7)

This correlates with the natural epidemiology of the disease. Analysing the presenting symptoms, fever was the universal presenting symptom present in all the cases studied $(100 \%)$ followed by headache $(91 \%)$, myalgia (86.6\%) and jaundice (58.2\%). In a similar study by Elizabeth F. Daher et al in the metropolitan city of Fortaleza in Brazil, the main symptoms included fever $(94.7 \%)$, myalgia (92\%), Jaundice (94\%) and Headache (74\%). Oliguria was found in $32.8 \%$ ( 24 cases). In the same study by Daher showed there is significant mortality in patients presenting with oliguria than the non-oliguric cases. Among the 3 cases who died due to Leptospirosis, 2 cases had Oliguric renal failure constituting $66 \%$ to mortality.

Among the 31 cases (46\%) presenting with ARF dialysis was needed in 17 patients (54.8\%), thus reflecting Acute Renal Failure particularly non-oliguric as a grave prognostic sign. In Western population, the incidence of renal failure was around $70-80 \%$ in various studies, but whereas in Indian setup it varies from $40-60 \%$.

Conjunctival suffusion was observed in 56 cases (83.6\%). The 1990 Madras studies had only 59\% having conjunctival signs, but the Western literature shows higher incidence (70-80\%), thus making conjunctival suffusion as a reliable clinical diagnostic marker of the disease.

The study showed hepatomegaly in 59 cases (81\%) and splenomegaly in 31 cases (46.3\%). South American studies by Rafael Geraldo et al showed lesser incidence of hepatomegaly (37\%) and Splenomegaly (21\%).

Analysing the haematological parameters, thrombocytopenia constituted the majority accounting for $88 \%$ (Totally 59 cases) with a significant $\mathrm{p}$ value of $<.05$. In the Madras study, 30\% had lower platelets with $26 \%$ having evidence of internalbleeding contributing to morbidity.

Abnormal liver function tests were found in $71.6 \%$ (48 cases). The notable abnormalities were significant direct hyperbilirubinae mia $(80.6 \%)(\mathrm{p}<0.05)$. In a similar study by Tatitanawat and Tanjatham et al, a total bilirubin of $>2.5$ $\mathrm{mg} / \mathrm{dL}$ was an independent risk factor for mortality. The Madras study showed $84.7 \%$ of patients having high Bilirubin and altered AST and ALT. In this study 48 cases (76\%) had AST $>40 \mathrm{u} / \mathrm{L}$ with the maximum being $860 \mathrm{u} / \mathrm{L} ; 73 \%$ had high ALT with the maximum being $898 \mathrm{u} / \mathrm{L}$. The study by Jaureguiberry et al found abnormal AST and ALT in 83 and $86 \%$ respectively with mean AST and ALT higher in nonsurvivors when compared to survivors of the disease.

Metabolic acidosis and ARDS was noted in 3 cases (4.5\%) with 1 death out of total 3 due to respiratory complication. 
Among the 67 patients admitted, 95.5\% received general treatment with intravenous fluids and specific treatment with IV Penicillin for moderate-to-severe cases (76.1\%) and milder uncomplicated cases were treated with oral Doxycycline (23.9\%). Blood transfusion was needed in 7 cases $(10.4 \%)$ who had anaemia, thrombocytopenia and bleeding manifestations.

\section{CONCLUSION}

Leptospirosis was found to be common in outdoor manual workers and farmers (53\%). Males are at high risk due to occupational exposure (71\%), the sex ratio being $2.5: 1$. The most common observed symptom was Fever (100\%), Headache (91\%) and Myalgia (86.6\%). Conjunctival suffusion was found in $83.6 \%$ of patients. Hepatomegaly was found in $88 \%$ patients and splenomegaly was found in $46.3 \%$. Anaemia was found in $32.8 \%$. Thrombocytopenia was present in $88 \%$ cases. Bleeding manifestations were found in $8.9 \% ; 58.2 \%$ had reversible hepatic damage; $4.5 \%$ patients developed ARDS; 46.3\% patients developed ARF. Crystalline Penicillin IV was the drug of choice in moderate-tosevere leptospirosis; $4.5 \%$ died due to complications.

\section{REFERENCES}

1. Himani D, Suman MK, Mane BG. Epidemiology of leptospirosis: an Indian perspective. Journal of Foodborne and Zoonotic Diseases 2013;1(1):372-82.

2. Petri WA. XXII infectious diseases. Cecil textbook of medicine. 21st edn. Chapter 396. Harcourt, Asia: WB Saunders Company 1761:2.

3. Faine S. Guidelines for the control of Leptospirosis. WHO Offset Publication 1982:67.

4. Sehgal SC, Murhekar MV, Sugunan AP. Andaman haemorrhagic fever in Andaman and Nicobar Islands. Proc of the South Asian workshop on diagnostic methods in leptospirosis. The Tamil Nadu M. G. R. Medical Univ, Madras 1995;69.

5. Shivakumar S. Leptospirosis - current scenario in India. Medicine Update 2008;18:800-6.

6. World Health Organization. Guidelines for the prevention and control of leptospirosis. Zoonosis division, National institute of communicable diseases, 22Shamnath marg, Dehli 110054, 2006.

7. Muthusethupathi MA, Shivakumar S, Suguna R, et al. Leptospirosis in Madras - a clinical and serological study. J Assoc Phys Ind 1995;43(7):456-8. 